\title{
Recovering tracer test input functions from fluid electrical conductivity logging in fractured porous rocks
}

\author{
S. A. Mathias, ${ }^{1}$ A. P. Butler, ${ }^{1}$ D. W. Peach, ${ }^{2}$ and A. T. Williams ${ }^{2}$ \\ Received 22 August 2006; revised 18 April 2007; accepted 30 April 2007; published 26 July 2007.
}

[1] A radially convergent tracer test was carried out in an unconfined Chalk aquifer of Berkshire, United Kingdom. Fluorescent tracers were injected into two boreholes lying $32 \mathrm{~m}$ (PL10A) and $54 \mathrm{~m}$ (PL10B) from the abstraction hole. The tracers were also mixed with an $\mathrm{NaCl}$ solution so that vertical distributions of tracer within the injection wells could be monitored using fluid electrical conductivity (FEC) logging. The breakthrough curve (BTC) from PL10A was unimodal and had a first arrival time of $14 \mathrm{~min}$. The BTC from PL10B exhibited two distinct peaks and a first arrival time of just 4 min. The tracer test input functions were derived by numerically modeling the observed FEC logs of the injection wells. These were then convoluted with a conventional, Fickian matrix diffusion dual-porosity model. The results suggested that the multiple peaks were due to the way in which the tracers left the injection wells and migrated into the aquifer. FEC log inversion proved to be an effective method for predicting borehole flow data obtained by flowmeters and recovering tracer test input functions for radially convergent tracer tests.

Citation: Mathias, S. A., A. P. Butler, D. W. Peach, and A. T. Williams (2007), Recovering tracer test input functions from fluid electrical conductivity logging in fractured porous rocks, Water Resour. Res., 43, W07443, doi:10.1029/2006WR005455.

\section{Introduction}

[2] Radially convergent tracer tests are often used for characterizing fractured rock formations. These involve pumping an abstraction well to obtain a quasi-steady radially convergent flow field. A tracer is then injected in a neighboring borehole which lies within the radially convergent flow field. Tracer concentrations are then monitored and recorded at the abstraction well.

[3] Model parameters are obtained by calibrating an appropriate model to the tracer concentration data observed in the abstraction water. Often the tracer injection is assumed to be an instantaneous process [Maloszewski and Zuber, 1990; Moench, 1995; Atkinson et al., 2000; Witthuser et al., 2003]. Alternatively, it is treated as a square wave [McKenna et al., 2001; Einsiedl and Maloszewski, 2005], or some form of exponential process [Becker and Charbeneau, 2000; Atkinson et al., 2001; Streetly et al., 2002; Brouyere et al., 2005].

[4] In the work described in this paper, the tracer is mixed with a saline solution. The vertical distribution of tracer within the injection well is then monitored at different times using a fluid electrical conductivity (FEC) probe as is done when performing a borehole dilution test [Michalski and Klepp, 1990; Brainerd and Robbins, 2004; West and Odling, 2007]. The resulting FEC logs are then inverted using a dilution test model [e.g., Tsang et al., 1990; Evans, 1995; Doughty, 2005] to obtain detailed, quantitative

\footnotetext{
${ }^{1}$ Department of Civil and Environmental Engineering, Imperial College London, London, UK.

${ }^{2}$ British Geological Survey, Wallingford, UK.

Copyright 2007 by the American Geophysical Union. 0043-1397/07/2006WR005455\$09.00
}

knowledge of where the tracer entered the aquifer and its distribution with time. This can then be convoluted with a tracer test model [e.g., Maloszewski and Zuber, 1985; Moench, 1995] so as to predict the tracer concentrations in the abstraction water.

\section{Test Description}

[5] A radially convergent tracer test was carried out at the Bottom Barn River augmentation abstraction well (BBA) situated in a Chalk aquifer in Berkshire, United Kingdom. The pump in the BBA was switched on at 09:18 on 27 April 2005 at a constant rate of $5.77 \mathrm{Ml} /$ day. Between 10:03 and $10: 13$ on 28 April 2005, $10 \mathrm{~g}$ of uranine and $2 \mathrm{~kg} \mathrm{NaCl}$, dissolved in $20 \mathrm{~L}$ of local tap water, were injected into a borehole $32 \mathrm{~m}$ away, referred to hereafter as PL10A. Between 16:14 and 16:17 on 28 April 2005, $25 \mathrm{~g}$ of amino $\mathrm{G}$ and $2.5 \mathrm{~kg} \mathrm{NaCl}$, also dissolved in $20 \mathrm{~L}$ of local tap water, were injected into a borehole $54 \mathrm{~m}$ away, PL10B. At 20:58 on 28 April 2005, pumping stopped because of an electrical fault. Uranine and amino $\mathrm{G}$ concentrations in the abstraction water were continuously monitored and recorded at the BBA using an automatically logged fluorometer (see observed breakthrough curves in Figures 1 and 2). The logging interval was $10 \mathrm{~s}$.

[6] Both injection wells were $100 \mathrm{~m}$ deep and cased down to $18 \mathrm{~m}$ at PL10A and $20 \mathrm{~m}$ at PL10B [Williams et al., 2006]. The tracer injection procedure was as follows: A $100 \mathrm{~m}$ length of plastic tube with an inside diameter of $2 \mathrm{~cm}$ was lowered into the injection well such that it spanned its full depth. The tracer solution was then poured into the tube. The volume of tracer solution was calculated such that the depth of the tracer slug spanned the submerged portion of the injection tube. Finally, the tube was manually extracted 


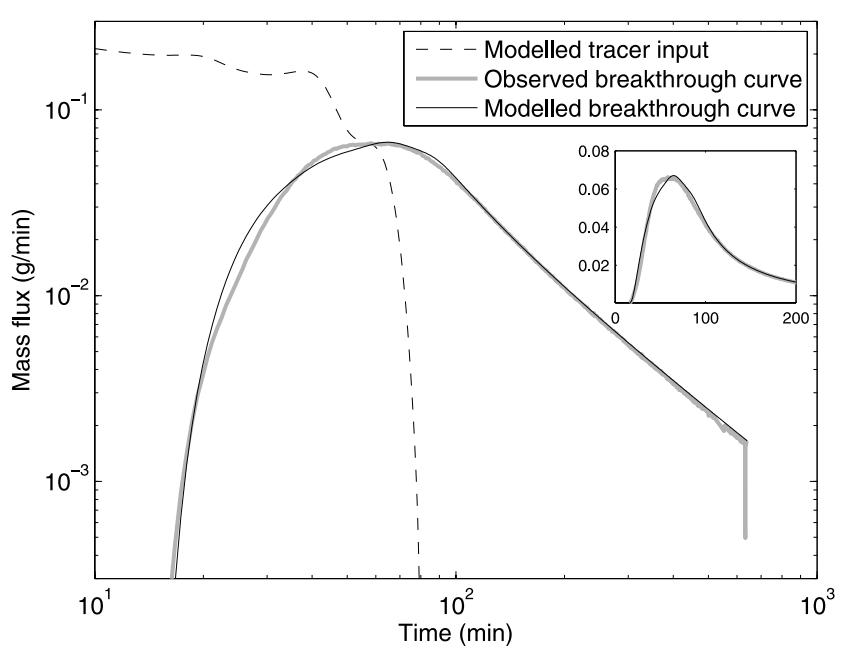

Figure 1. Plots of modeled tracer input for PL10A, the observed PL10A tracer (uranine) breakthrough curve at the BBA, and the modeled breakthrough curve obtained by convoluting the SFM $\left(t_{a}=13.2 \mathrm{~min}, t_{c f}=2.3 \mathrm{~min}\right.$, and assuming $100 \%$ ultimate mass recovery) with the tracer input function. For comparison, the observed and modeled breakthrough curves are also plotted on linear scales in the insert.

so as to leave the tracer column exposed to the aquifer. Pulling the tube up took around $10 \mathrm{~min}$ at PL10A and just 3 min at PL10B.

[7] While the aim was to achieve an initial tracer concentration uniform with depth it is recognized that this was not achieved for at least three reasons: First, even if a uniform tracer concentration is achieved within the injection tube, once the tube is withdrawn the concentration distribution with depth becomes inversely proportional to the injection well cross-sectional area, which is highly variable. (This variability is not unusual in Chalk boreholes and is caused by the variable fracture density in the formation; specifically boreholes are generally enlarged in the zone of water table fluctuation.) Secondly, during the time in which the injection tube is withdrawn, the exposed portion of the tracer column is already affected by the flow field of the aquifer and the borehole. Thirdly, the method of removal of the injection tube also adds to the nonuniformity. It is removed by hand and therefore it is impossible for it to be raised in a completely smooth manner. This can result in a pulsed tracer injection, especially when the hose is removed rapidly as was the case for PL10B.

[8] Figures 1 and 2 show plots of observed mass flux at the abstraction well. Tracer mass recovery was good with $79 \%$ from PL10A and $99 \%$ from PL10B. The first thing to note is that while tracer traveled the $32 \mathrm{~m}$ distance from PL10A to BBA in around $14 \mathrm{~min}$, tracer traveled the $54 \mathrm{~m}$ distance from PL10B to BBA in just 4 min. Secondly, the PL10A breakthrough curve (BTC) has a broad peak while the PL10B BTC has at least two peaks, which are themselves noisy and contain subpeaks. Such peaks are traditionally assumed to be due to multiple flow pathways [e.g., Streetly et al., 2002].

[9] Chalk aquifers possess dual porosity whereby flow predominantly occurs through fractures while water stored in the matrix is largely immobile [Price et al., 1993; Williams et al., 2006]. However, solute exchange between the fractures and the matrix can occur by molecular diffusion [Barker, 1993]. Consistent with this, both BTCs tend toward the characteristic log-log $-3 / 2$ slope for large times [Tsang, 1995; Haggerty et al., 2000].

\section{Calculation of Tracer Test Input Function}

[10] A quantitative description of the way that the tracers leave the injection wells (the tracer test input function) is required to better constrain the interpretation of the tracer test breakthrough curves at the abstraction well. The methodology used to obtain a tracer test input function is as follows:

[11] 1. Identify possible flow horizons from integrated geophysical data (temperature, upflow, FEC etc.);

[12] 2. Estimate flow rates at flow horizons by fitting a dilution test model (discussed below) to the FEC logs;

[13] 3. The tracer test input functions are then obtained as a mass flux by multiplying modeled concentrations at outflowing horizons by their respective outflow rates.

\subsection{Identifying Flow Horizons}

[14] During the pumping at BBA, a suite of geophysical logs were obtained for both PL10A and PL10B. These included calliper, gamma, temperature and upflow and can be seen alongside the FEC logs in Figures 3 and 4.

[15] The flow horizon search starts with the upflow logs. Gains in absolute flow are caused by inflowing horizons while losses or changes in flow direction are caused by outflowing horizons. Borehole flow data were obtained using both an impeller and heat pulse flowmeter.

[16] Impeller flowmeter measurement involves lowering an impeller down a borehole at a fixed rate, $v_{\text {winch }}$ and

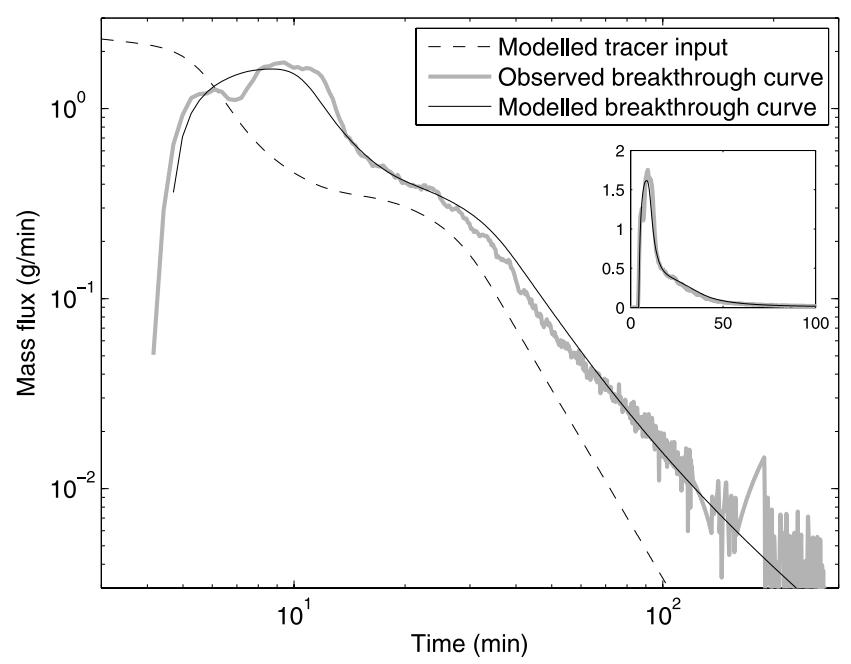

Figure 2. Plots of modeled tracer input for PL10B, the observed PL10B tracer (amino G) breakthrough curve at the BBA, and the modeled breakthrough curve obtained by convoluting the SFM $\left(t_{a}=4.5 \mathrm{~min}, t_{c f}=13.7 \mathrm{~min}\right.$, and assuming $100 \%$ ultimate mass recovery) with the tracer input function. For comparison, the observed and modeled breakthrough curves are also plotted on linear scales in the insert. 

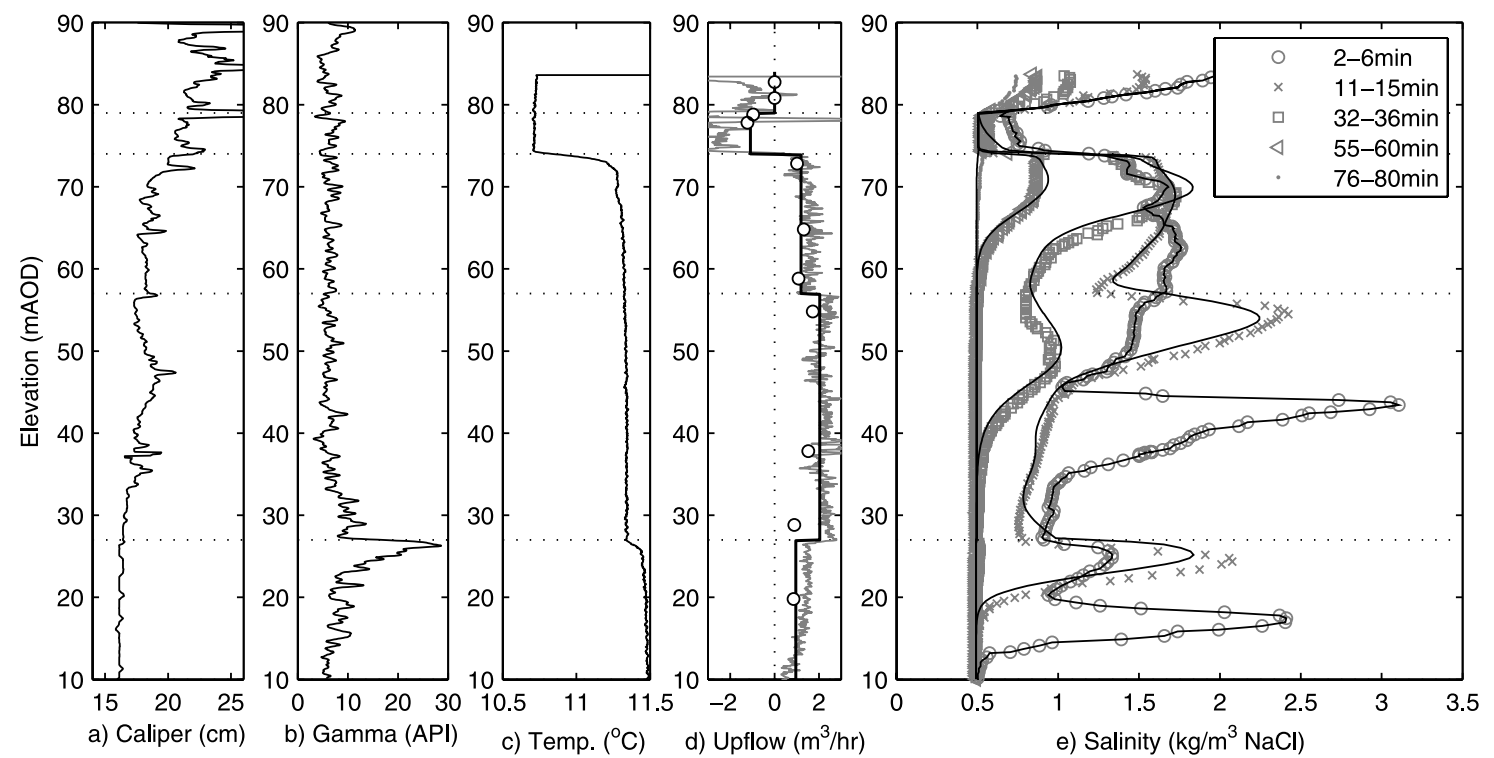

Figure 3. (a-e) Geophysical logging in PL10A while pumping the Bottom Barn abstraction well. Figure 3d shows upflow estimated from the impeller flowmeter (gray line), the heat pulse flowmeter (circles), and numerical inversion of the FEC logs (thick black line). Figure 3e shows the fluid electrical conductivity (FEC) logs recorded after the tracer injection. All FEC profiles were down runs with start and finish times of each run as indicated in the legend. The solid lines shown in Figure 3e are the FEC logs generated from the numerical model. The horizontal dotted lines across all the plots show the elevations of the flow horizons used for numerical inversion of the FEC logs.

logging the revs/min of the impeller, $\omega$. The net upflow velocity, $v_{u p}$ can then be found from

$$
v_{u p}=\omega r_{i m p}-v_{\text {winch }}
$$

where $r_{i m p}$ is the 'effective' radius of the impeller, which is approximately $37.5 \mathrm{~mm}$ (in practice, an empirical expression is obtained from a calibration exercise). The flow rate is then obtained by multiplying the velocity by the borehole cross-sectional area obtained from the caliper log measure- ments. Note that noise in the flow impeller profiles is partially due to error in the borehole area measurement.

[17] The main shortcoming of impeller flowmeters is their lack of sensitivity to low-velocity flow. The most commonly used impeller flowmeters usually stall at velocities of 1 to $1.5 \mathrm{~m} / \mathrm{min}$ [Keyes, 1990]. For smaller flow rates, a heat pulse flowmeter is more appropriate.

[18] The heat pulse flowmeter was originally developed by Dudgeon et al. [1975]. An electrical heating grid, located horizontally between two thermistors located vertically
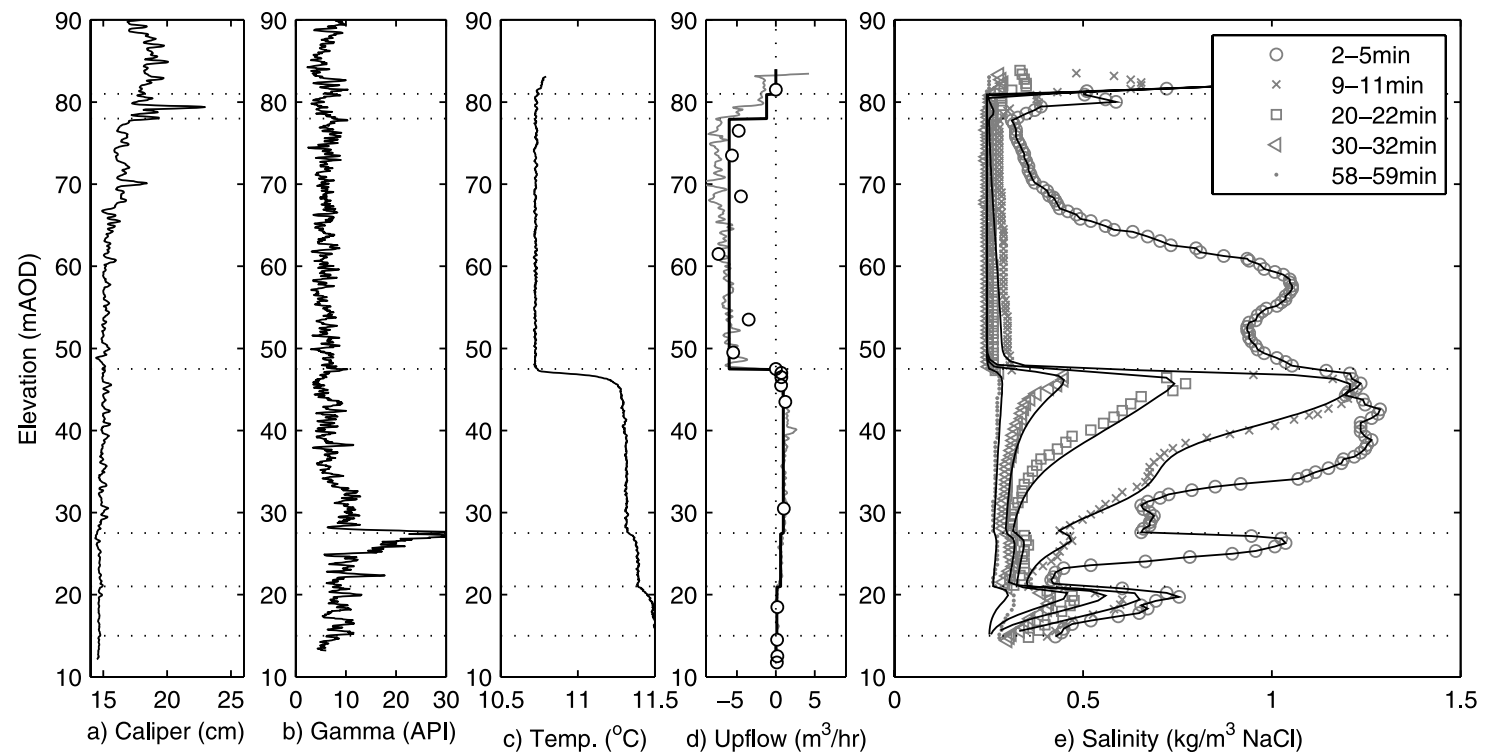

Figure 4. Geophysical logging in PL10B while pumping the Bottom Barn abstraction well. Details are identical to those described in the caption for Figure 3. 
above and below, is heated by a short pulse of electric current, which is triggered from the land surface. The heated lens of water is moved toward one of the thermistors by the vertical component of flow in the borehole. The arrival of the heat pulse is plotted on a chart recorder. If the heat pulse is detected by the upper thermistor, flow is upward and vice versa. The flow velocity can then be calculated by dividing the distance between the element and thermistor by the respective traveltime. The flow rate can then be obtained by multiplying by the local cross-sectional area from the caliper $\log$.

[19] Figures $3 \mathrm{~d}$ and $4 \mathrm{~d}$ show the impeller and heat pulse flow measurements are generally in good agreement, therefore the continuous log from the impeller flowmeter can be used with confidence.

[20] The upflow log for PL10A (Figure 3d) indicates an inflow at $27 \mathrm{mAOD}$ (above ordinance datum) and two outflows at 57 and 74 mAOD. The upflow log for PL10B (Figure 4d) indicates an inflow at $78 \mathrm{mAOD}$ and an outflow at $47.5 \mathrm{mAOD}$.

[21] The temperature logs can also be used for flow horizon identification. Aquifers generally possess a positive temperature gradient with depth. When a borehole is installed in fractured rock, discrete flow horizons originally separated become hydraulically connected. This can result in hydraulic gradients within the borehole and a flow of water between the flow horizons. Accordingly a sharp change in temperature manifests itself in the presence of a flow horizon. The temperature log for PL10B (Figure 4c) indicates additional small flow horizons at 21 and $27.5 \mathrm{mAOD}$. From the FEC logs in Figure 4e it can be seen that these horizons have a diluting effect implying that they are inflowing horizons.

[22] The FEC logs (Figures 3e and 4e) also show that there is an upflow from the base of both boreholes. Figure 3e also indicates a further diluting feature at $79 \mathrm{mAOD}$ in PL10A, while Figure 4e indicates an additional feature at $81 \mathrm{mAOD}$ in PL10B.

[23] In PL10A, the temperature, upflow and FEC logs have indicated at least four flow horizons at 27, 57, 74 and 79 mAOD. While the 57, 74 and 79 mAOD horizons are supported by features in the calliper log (Figure 3a), the 27 mAOD horizon corresponds with a large peak in the gamma log (Figure 3b) which has been identified as the 3.5m-thick hard layer known as the Chalk Rock, situated at the base of the Upper Chalk formation (or more specifically, the base of the Lewes Nodular Chalk Formation) [Schurch and Buckley, 2002].

[24] In PL10B, the temperature, upflow and FEC logs have indicated at least five flow horizons at 21, 27.5, 47.5, 78 and $81 \mathrm{mAOD}$. Horizon $27.5 \mathrm{mAOD}$ corresponds with the Chalk Rock feature in the gamma log.

\subsection{Dilution Test Modeling}

[25] The method of tracer injection used in this paper is similar to that used for single well dilution testing [Michalski and Klepp, 1990; Tsang et al., 1990; Ward et al., 1998; Doughty, 2005]. The dilution tests were conducted as follows: A FEC probe is lowered down the borehole to obtain a measure of background conductivity with depth. A $100 \mathrm{~m}$ tube with an inside diameter of $2.0 \mathrm{~cm}$ is then lowered down to the base of the borehole and filled with a well-mixed saline solution. The tube is then retrieved so as to provide a close to uniform, elevated conductivity along the borehole. As water enters and leaves the borehole via flow horizons the saline solution is diluted. The rate of dilution is then monitored by subsequent FEC logging. The result is a set of FEC profiles for a sequence of different times.

[26] The FEC logs can be converted to saline concentration using [Doughty, 2005]

$$
c=\frac{1870-\sqrt{1870^{2}-80 F E C_{20}}}{80}
$$

where $c$ is the saline concentration measured in $\mathrm{kg} / \mathrm{m}^{3}$ of $\mathrm{NaCl}, F E C_{20}$ is fluid electrical conductivity at $20^{\circ} \mathrm{C}$ measured in $\mu \mathrm{S} / \mathrm{cm}$, which is found from [Doughty, 2005]

$$
F E C_{20}=\left[1+0.024\left(T-20^{\circ} \mathrm{C}\right)\right] F E C_{T}
$$

where $F E C_{T}$ was measured at a temperature, $T$.

[27] The dilution test data can be inverted to acquire discrete flow rates associated with flow horizons using a dilution test model. The model assumes steady state flow and that the borehole is fully mixed laterally such that solute concentrations within the borehole can be described in one dimension using [Tsang et al., 1990]

$$
A(z) \frac{\partial c}{\partial t}=\frac{\partial}{\partial z}\left[D(z) \frac{\partial c}{\partial z}-Q_{z}(z) c\right]+q_{\text {in }}(z) c_{0}-q_{\text {out }}(z) c
$$

where $A(z)\left[L^{2}\right]$ is the borehole cross-sectional area, $c$ $\left[M L^{-3}\right]$ is solute concentration in the borehole, $z[L]$ is elevation, $D=\alpha_{z}\left|Q_{z}\right|\left[L^{4} T^{-1}\right]$ is a coefficient characterizing total dispersion, $\alpha_{z}[L]$ is the dispersivity longitudinal to the borehole, $c_{0}(z)\left[M L^{-3}\right]$ is the local background concentration, $q_{\text {in }}\left[L^{2} T^{-1}\right]$ and $q_{\text {out }}\left[L^{2} T^{-1}\right]$ are inflow and outflows associated with flow horizons, and $Q_{z}\left[L^{3} T^{-1}\right]$ is volumetric flow longitudinal to the borehole found from

$$
Q_{z}(z)=\int_{z_{\min }}^{z}\left(q_{\text {in }}-q_{\text {out }}\right) d z
$$

[28] The initial and boundary conditions take the form

$$
c(z, 0)=c_{i}(z) ;\left.\quad \frac{\partial c}{\partial z}\right|_{z=0}=\left.\frac{\partial c}{\partial z}\right|_{z=z_{\max }}=0
$$

where $c_{i}\left[M L^{-3}\right]$ is the solute profile immediately after the perturbation and $z_{\min }[L]$ and $z_{\max }[L]$ are the elevations of the borehole base and the water table, respectively.

[29] The equations were solved by discretizing in space using finite differences (specifically, using a central difference approximation for the advection term) to obtain a series of ordinary differential equations with respect to time. These were then solved using the numerical integrator, ODE45, available with any standard copy of MATLAB. ODE45 is based on an explicit Runge-Kutta formula, the Dormand-Prince pair [Dormand and Prince, 1980].

[30] A space step of $0.1 \mathrm{~cm}$ was used for all simulations to ensure that the numerical Peclet number $\left(\Delta z / \alpha_{z}\right)$ was much less than 2.0, which is required for stability purposes [e.g., Sun, 1996]. Because, ODE45 uses an adaptive time 
Table 1. Inflows and Outflows Spread Over a Space Step of $0.1 \mathrm{~m}$ Obtained From Dilution Test Modeling of PL10A

\begin{tabular}{ccc}
\hline Elevation, mAOD & Inflow, $\mathrm{m}^{3} / \mathrm{hr}$ & Outflow, $\mathrm{m}^{3} / \mathrm{hr}$ \\
\hline 79.0 & 1.08 & 0.00 \\
74.0 & 0.00 & 2.28 \\
57.0 & 0.00 & 0.84 \\
27.0 & 1.08 & 0.00 \\
10.0 & 0.96 & 0.00 \\
\hline
\end{tabular}

grid, the selection of a time step was not necessary. It was therefore possible to solve for the exact time and depth of each observed FEC measurement.

[31] The dilution test model was calibrated against the dilution test data from the PL10A and PL10B tracer injections. Modeled output (solid lines) are plotted alongside the observed data (markers) in Figures 3e and 4e. The background concentration profiles, $c_{0}$ were obtained from FEC logs immediately prior to the tracer injections. Because the first FEC profiles ( 2 to $6 \mathrm{~min}$ for PL10A and 2 to $5 \mathrm{~min}$ for PL10B) were far from uniform it was decided to use these as the initial conditions, $c_{i}$. The cross-sectional areas of the boreholes, $A(z)$ were obtained from the calliper logs.

[32] In many formations an artificially induced uniform concentration can be achieved by mechanically mixing the injection well. However, because of the short time taken for the tracer to leave the borehole, this methodology is not suitable for use in these boreholes. All the tracer would have left before a uniform condition could be achieved.

[33] An automatic calibration method has been proposed for dilution test modeling by Evans [1995]. However, it was found that the tailoring of an appropriate objective function that captured the visual aspects of the model fit we desired became so subjective that a manual calibration was considered more appropriate.

[34] The resulting set of inflows and outflows are shown in Tables 1 and 2. These are also plotted alongside the flowmeter logs in Figures $3 \mathrm{~d}$ and $4 \mathrm{~d}$, as the heavier lines, where it can be seen that there is a very good correspondence. A uniform dispersivity of $0.1 \mathrm{~m}$ was needed for PL10A and $0.5 \mathrm{~m}$ for PL10B.

[35] Of particular interest is that, in the models that offered the best visual fit, tracer only entered the aquifer at two flow horizons in PL10A and one flow horizon in PL10B despite the presence of a number of different peaks in the BBA breakthrough curve (see Figure 2).

\subsection{Tracer Test Input Functions}

[36] Figures 5 and 6 show plots of the outlet and mean concentrations from PL10A and PL10B, respectively.

[37] The mean concentration was calculated from

$$
\bar{c}(t)=\frac{\int_{z_{\min }}^{z_{\max }} A(z) c(z, t) d z}{\int_{z_{\min }}^{z_{\max }} A(z) d z}
$$

It can be seen that the modeled and observed mean concentration time series compare well for both boreholes.

[38] Of particular interest is that while the mean concentrations decline monotonically, the outlet concentration time series are nonmonotonic showing a number of different peaks. These peaks are caused by the nonuniform injection concentration combined with variations in the borehole cross-sectional area. It is postulated that these peaks in the outlet concentration time series are responsible for the peaks seen in the breakthrough curve from PL10B (Figure 2). They are not seen in PL10A because of the longer traveltime, which allows extra attenuation to occur because of matrix diffusion, as compared to PL10B.

[39] In theory, we should be able to test this hypothesis by convoluting the outlet mass flux time series, $m_{0}(t)$ with a transfer function, $g(t)$

$$
c_{e}(t)=\frac{1}{Q} \int_{0}^{t} m_{0}(\tau) g(t-\tau) d \tau
$$

In the first instance, the two-parameter, single fracture model (SFM) of Maloszewski and Zuber [1985] seems appropriate such that

$$
g(t)=\left[\frac{t_{a}^{2}}{4 \pi t_{c f}\left(t-t_{a}\right)^{3}}\right]^{1 / 2} \exp \left[-\frac{t_{a}^{2}}{4 t_{c f}\left(t-t_{a}\right)}\right], \quad t>t_{a}
$$

where $t_{a}[T]$ is the advective traveltime, $M[M]$ is the mass of tracer injected, $c_{e}\left[M L^{-3}\right]$ is the tracer concentration and $Q\left[L^{3} T^{-1}\right]$ is the abstraction rate and $t[T]$ is time after injection. The parameter $t_{c f}$ is often referred to as the characteristic fracture diffusion time [Barker et al., 2000; Atkinson et al., 2001] and is found from

$$
t_{c f}=\frac{a^{2}}{4 \phi D_{E}}
$$

where $a[L]$ is the fracture aperture, $\phi[-]$ is the matrix porosity and $D_{E}\left[L^{2} T^{-1}\right]$ is the effective diffusion coefficient of the tracer within the rock matrix.

[40] However, because of the time taken to withdraw the tracer injection tube and perform the first FEC log, a sizable function of the injected tracer mass has already left the borehole before the first FEC log (after tracer injection) is completed. The mass of $\mathrm{NaCl}$ (minus the background levels) present in the first FEC logs was $1.67 \mathrm{~kg}$ (of $2.0 \mathrm{~kg}$ $\mathrm{NaCl}$ ) and $0.68 \mathrm{~kg}$ (of $2.5 \mathrm{~kg} \mathrm{NaCl}$ ) in PL10A and PL10B, respectively. Therefore too much tracer has been lost prior to logging to allow complete recovery of the tracer test input function.

\section{Application of Hypothetical Tracer Input Functions}

[41] As stated above, it is impossible to recover the entire tracer input functions because the first FEC log is completed

Table 2. Inflows and Outflows Spread Over a Space Step of $0.1 \mathrm{~m}$ Obtained From Dilution Test Modeling of PL10B

\begin{tabular}{ccc}
\hline Elevation, mAOD & Inflow, $\mathrm{m}^{3} / \mathrm{hr}$ & Outflow, $\mathrm{m}^{3} / \mathrm{hr}$ \\
\hline 81.0 & 1.22 & 0.00 \\
78.0 & 4.82 & 0.00 \\
47.5 & 0.00 & 7.00 \\
27.5 & 0.36 & 0.00 \\
21.0 & 0.48 & 0.00 \\
15.0 & 0.12 & 0.00 \\
\hline
\end{tabular}




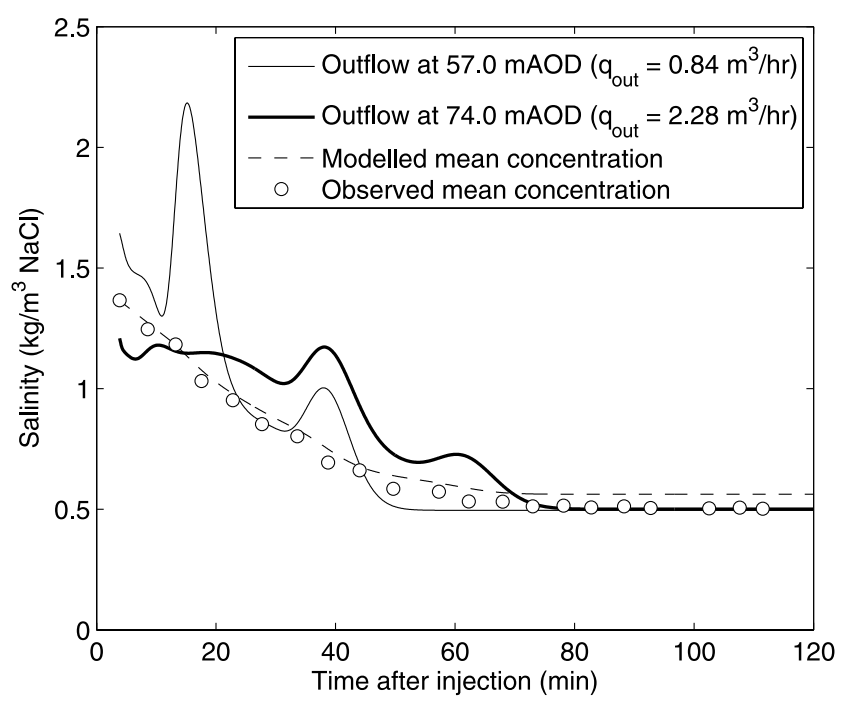

Figure 5. Plots of outlet and mean concentrations for PL10A.

several minutes after the tracer injection. However, a complete hypothetical tracer input function can be developed by assuming that the tracer concentration in the injection tube was perfectly uniform and released instantaneously. Under such conditions, the initial concentration profile will take the form

$$
c_{i}(z)=\frac{M}{\left(z_{\max }-z_{\min }\right) A(z)}+c_{0}
$$

where $M$ is the mass of tracer; $z_{\min }$ and $z_{\max }$ are the borehole-base and water table elevations, respectively; $A$ is the borehole area; and $c_{0}$ is the background tracer concentration.

[42] If we then apply the flow fields defined by the flows in Tables 1 and 2 and run the dilution test model forward, we then get the mass fluxes, $m_{0}$ of the tracer injection from

$$
m_{0}(t)=\int_{z_{1}}^{z_{2}} q_{\text {out }}(z) c(z, t) d z
$$

where $q_{\text {out }}$ is the water flux out of the injection well and $z_{1}$ and $z_{2}$ are the elevations of the lower and upper extents of an outflowing horizon.

[43] The tracer input functions were convoluted with the SFM and the parameters $t_{a}$ and $t_{c f}$ were obtained by minimizing the root mean squared error (RMSE) between the modeled and the observed tracer breakthrough curves (i.e., the data shown in Figures 1 and 2).

[44] Convolution was achieved using the CONV function available with MATLAB. CONV obtains the inverse fast Fourier transform of the product of the fast Fourier transforms of $m_{0}(t)$ and $g(t)$ (equation (9)). The minimization of the RMSE was achieved using the MATLAB function, FMINSEARCH. This uses the simplex search method of Lagarias et al. [1998] to find the minimum of a function local to a seed value which the user must specify a priori. Such a method is appropriate here because the SFM only has two unknown parameters.
[45] Figure 1 shows the hypothetical mass flux time series at the injection well and the abstraction well along with the observed mass flux at the abstraction well for the PL10A injection. Because the flow from PL10A at the 57 mAOD horizon was much smaller than at the $74 \mathrm{mAOD}$ horizon (see Table 1), it was not possible to confidently delineate a separate set of parameters for both horizons. Therefore, to conserve mass, the mass fluxes from both horizons were added together to give the single modeled tracer input seen in Figure 1. The parameters derived from the PL10A BTC consequently represent the composite response of both horizons. The correspondence between the observed and modeled breakthrough curves is very good. Note that the multiple peaks in the injection function are lost because of the dispersion caused by matrix diffusion.

[46] Figure 2 shows the hypothetical mass flux time series at the injection well and the abstraction well along with the observed mass flux at the abstraction well for the PL10B injection. The injection function does not show the multiple peaks present in the observed breakthrough curve indicating that the tracer release from the injection tube was also nonuniform. However, the correspondence between the observed and modeled abstraction mass flux is very good.

[47] The simulated first FEC $\operatorname{logs}$ (i.e., 2-6 min and 25 min for PL10A and PL10B, respectively) did not compare well with the observed profiles, which suggests that tracer release from the injection tubes was nonuniform in both PL10A and PL10B. This is probably because the injection hose was removed very rapidly which is known to lead to nonuniform tracer emplacements. In practice, it is not possible to obtain a uniform instantaneous tracer emplacement in $80 \mathrm{~m}$ of borehole and so a compromise between speed and uniformity has to be made. We were aware that a lot of tracer would leave the borehole in a short space of time and so felt it important to inject the tracer as rapidly as possible.

[48] The calibrated parameters for PL10A were $t_{a}=$ $13.2 \mathrm{~min}$ and $t_{c f}=2.3 \mathrm{~min}$, and for PL10B were $t_{a}=$ $4.5 \mathrm{~min}$ and $t_{c f}=13.7 \mathrm{~min}$. Calculating corresponding

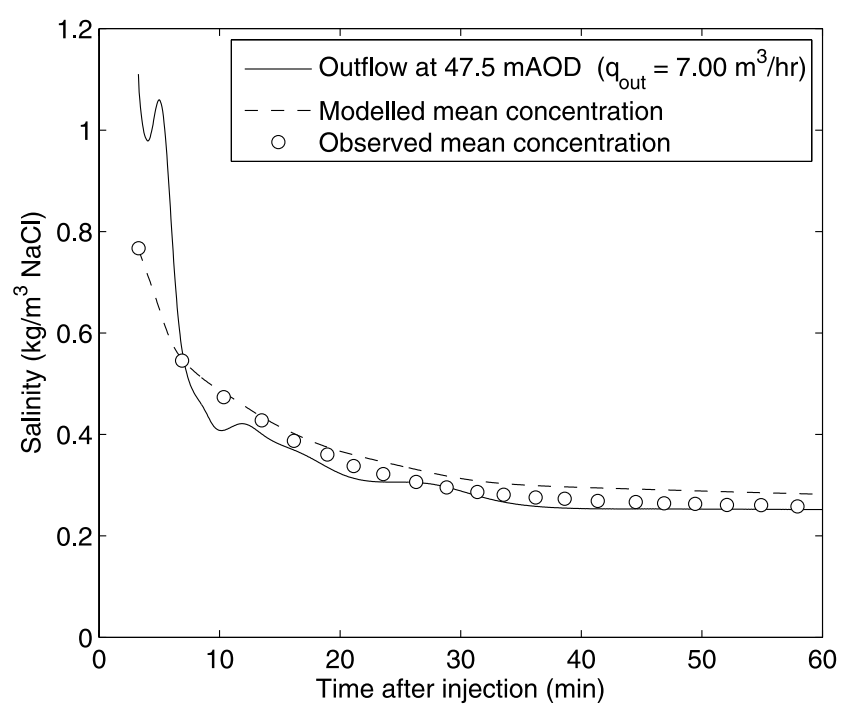

Figure 6. Plots of outlet and mean concentrations for PL10B. 
fracture apertures from equation (10) requires knowledge of the matrix porosity and effective diffusion coefficients for the two tracers.

[49] Following a regression analysis of porosity and diffusion coefficient data for chalk samples from the United Kingdom [Hill, 1984; Grathwohl, 1998; Witthuser et al., 2003], Denmark [Witthuser et al., 2003, 2006] and Israel [Polak et al., 2002; Witthuser et al., 2003, 2006], Witthuser et al. [2006] suggested that

$$
\frac{D_{E}}{D_{a q}} \approx \phi^{2.57}
$$

where $D_{a q}\left[L^{2} T^{-1}\right]$ is the aqueous diffusion coefficient of the tracer.

[50] Witthuser et al. [2000], Table 1 published a value of $D_{a q}=4.54 \times 10^{-10} \mathrm{~m}^{2} / \mathrm{s}$ for uranine. A comparison of reservoir depletion data for uranine and amino $G$ in limestone (presented by Greswell et al. [1998, Figure 9]) suggests that the same $D_{a q}$ can also be used for amino $\mathrm{G}$. Note that limestone has the same chemical composition as chalk.

[51] The matrix porosity at PL10A (above 40 mAOD) ranges between 0.35 and 0.45 [Wheater et al., 2007, Figure 5]. Assuming a matrix porosity of 0.40 , equation (13) gives an effective diffusion coefficient of $4.3 \times 10^{-11} \mathrm{~m}^{2} / \mathrm{s}$. It follows from equation (10) that typical apertures for the PL10A and PL10B BTCs were $98 \mu \mathrm{m}$ and $238 \mu \mathrm{m}$, respectively.

[52] For comparison, Atkinson et al. [2001] estimated a fracture aperture of $460 \mu \mathrm{m}$ at a Chalk site in Norfolk, United Kingdom while Witthuser et al. [2003] estimated fracture apertures of $397 \mu \mathrm{m}$ and $405 \mu \mathrm{m}$ at a Chalk site in the Negev, Israel. All of these values are small, which is consistent with the fact that field-scale tests generally lead to overestimates of effective diffusion coefficients [Zhou et al., 2007]. Zhou et al. [2006] suggest that this is due to the effective diffusion coefficient parameter lumping together additional processes such as diffusion into stagnant water within in fractures, infilling materials within fractures and degraded matrix zones.

\section{Conclusions}

[53] Radially convergent tracer tests can be useful tools for gaining insights into transport processes in dual-porosity aquifers. This paper has shown the importance of characterizing the input function, particularly where tracer enters the aquifer through a small number of discrete outflows and when the arrival time is comparable with the time of tracer injection. FEC logging and dilution test modeling conducted on two boreholes in a Chalk aquifer suggest that tracer traveled through just one or two pathways (Figures 3 and 4). The multiple peaks seen in one of the BTC were probably due to peaks in the release of tracer from the injection well caused by the diluting effects associated with borehole cross-sectional area irregularities and the tracer injection procedure itself. Overall, FEC log inversion has proved to be an effective method for predicting borehole flow data obtained by flowmeters and recovering tracer test input functions for radially convergent tracer tests.
[54] Acknowledgments. Funding through the NERC LOCAR research program is gratefully acknowledged (project NER/T/S/2001/ 00941). The authors would like to thank Tim Atkinson at University College London for the use of the fluorometer and Tony Scott at the Environment Agency, United Kingdom, for access to and use of the Bottom Barn abstraction well. The assistance of Alex Gallagher, Lou Maurice, Dave Buckley, and Ian Woods from the British Geological Survey for help in collecting the field data is gratefully acknowledged. The authors would also like to thank the editors and reviewers of Water Resources Research for their constructive comments and suggestions.

\section{References}

Atkinson, T. C., R. S. Ward, and E. O'Hannelly (2000), A radial-flow tracer test in Chalk: Comparison of models and fitted parameters, in Tracers and Modelling in Hydrogeology, edited by A. Dassargues, IAHS Publ., $262,7-15$.

Atkinson, T. C., J. A. Barker, R. S. Ward, and R. G. Low (2001), Radon: An indicator of solute transport in double-porosity aquifers, in New Approaches Characterizing Groundwater Flow, edited by K. P. Seiler and S. Wohnlich, pp. 441-445, A. A. Balkema, Brookfield, Vt.

Barker, J. A. (1993), Modelling groundwater flow and transport in the Chalk, in The Hydrogeology of the Chalk of North-West Europe, edited by R. A. Downing, M. Price, and G. P. Jones, pp. 59-66, Clarendon, Oxford, U. K.

Barker, J. A., T. E. J. Wright, and B. A. Fretwell (2000), A pulsed-velocity method of double-porosity solute transport modelling, in Tracers and Modelling in Hydrogeology, edited by A. Dassargues, IAHS Publ., 262, 297-302.

Becker, M. W., and R. J. Charbeneau (2000), First-passage time transfer functions for groundwater tracer tests conducted in radially convergent flow, J. Contam. Hydrol., 40, 299-310, doi:10.1016/S01697722(99)00061-3.

Brainerd, R. J., and G. A. Robbins (2004), A tracer dilution method for fracture characterization in bedrock wells, Ground Water, 42(5), 774780, doi:10.1111/j.1745-6584.2004.tb02731.x.

Brouyere, S., G. Carabin, and A. Dassargues (2005), Influence of injection conditions on field tracer experiments, Groundwater, 43(3), 389-400, doi:10.1111/j.1745-6584.2005.0041.x.

Dormand, J. R., and P. J. Prince (1980), A family of embedded RungeKutta formulae, J. Comput. Appl. Math., 6, 19-26, doi:10.1016/0771050X(80)90013-3.

Doughty, C. (2005), Signatures in flowing fluid electric conductivity logs, J. Hydrol., 310, 157-180, doi:10.1016/j.jhydrol.2004.12.003.

Dudgeon, C. R., M. J. Green, and W. J. Smedmor (1975), Heat-pulse flowmeter for boreholes: Medmenham, Tech. Rep. TR4, Water Res. Cent., Swindon, U. K.

Einsiedl, F., and P. Maloszewski (2005), Tracer tests in fractured rocks with a new fluorescent dye-Pyrene-1,3,6,8-tetra sulphonic acid (PTS), Hydrol. Sci. J., 50(3), doi:10.1623/hysj.50.3.543.65026.

Evans, D. G. (1995), Inverting fluid conductivity logs for fracture inflow parameters, Water Resour. Res., 31(12), 2905-2916.

Grathwohl, P. (1998), Diffusion in Natural Porous Media: Contaminant Transport, Sorption/Desorption and Dissolution Kinetics, Kluwer Acad., London.

Greswell, R., K. Yoshida, J. H. Tellam, and J. W. Lloyd (1998), The microscale hydrogeological properties of the Lincolnshire limestone, UK, Q. J. Eng. Geol., 31, 181-197.

Haggerty, R., S. A. McKenna, and L. C. Miggs (2000), On the late-time behaviour of tracer test breakthrough curves, Water Resour. Res., 36(12), $3467-3479$.

Hill, D. (1984), Diffusion coefficients of nitrate, chloride, sulphate and water in cracked and uncracked chalk, J. Soil Sci., 35, 27-33, doi:10.1111/j.1365-2389.1984.tb00256.x.

Keyes, W. S. (1990), Borehole geophysics applied to groundwater investigations, U.S. Geol. Surv. Tech. Water Resour. Invest., Book 2, Chap. E2.

Lagarias, J. C., J. A. Reeds, M. H. Wright, and P. E. Wright (1998), Convergence properties of the Nelder-Mead simplex method in low dimensions, SIAM J. Optim., 9(1), 112-147, doi:10.1137/S1052623496303482.

Maloszewski, P., and A. Zuber (1985), On the theory of tracer experiments in fissured rocks with a porous matrix, J Hydrol., 79, 333-358, doi:10.1016/0022-1694(85)90064-2.

Maloszewski, P., and A. Zuber (1990), Mathematical modelling of tracer breakthrough in short-term experiments in fissured rocks, Water Resour. Res., 26(7), 1517-1528. 
McKenna, S. A., L. C. Meigs, and R. Haggerty (2001), Tracer tests in a fractured dolomite: 3. Double-porosity, multiple-rate mass transfer processes in convergent flow tracer tests, Water Resour. Res., 37(5), $1143-$ 1154.

Michalski, A., and G. M. Klepp (1990), Characterization of transmissive fractures by simple tracing of in-well flow, Ground Water, 28(2), 191198, doi:10.1111/j.1745-6584.1990.tb02246.x.

Moench, A. F. (1995), Convergent radial dispersion in a double porosity aquifer with fracture skin: Analytical solution and application to a field experiment in fractured chalk, Water Resour. Res., 31(8), 1823-1835.

Polak, A., R. Nativ, and R. Wallach (2002), Matrix diffusion in northern Negev fractured chalk and its correlation to porosity, J. Hydrol., 268, 203-213, doi:10.1016/S0022-1694(02)00176-2.

Price, M., R. A. Downing, and W. M. Edmunds (1993), The Chalk as an aquifer, in The Hydrogeology of the Chalk of North-West Europe, edited by R. A. Downing, M. Price, and G. P. Jones, pp. 35-58, Clarendon, Oxford, U. K.

Schurch, M., and D. Buckley (2002), Integrating geophysical and hydrochemical borehole-log measurements to characterize the Chalk aquifer, Berkshire, United Kingdom, Hydrogeol. J., 10, 610-627, doi:10.1007/ s10040-002-0220-x.

Streetly, H. R., A. C. L. Hamilton, C. Betss, J. H. Tellam, and A. W. Herbert (2002), Reconnaissance tracer tests in the Triassic sandstone aquifer north of Liverpool, UK, Q. J. Eng. Geol., 35(2), 167-178, doi:10.1144/1470-9236/2000-30.

Sun, N. Z. (1996), Mathematical Modeling of Groundwater Pollution, Springer, New York.

Tsang, C. F., P. Hufschmeid, and F. V. Hale (1990), Determination of fracture inflow parameters with a borehole fluid conductivity logging method, Water Resour. Res., 26(4), 561-578.

Tsang, Y. W. (1995), Study of alternative tracer tests in characterizing transport in fractured rocks, J. Geophys. Res., 22(11), 1421-1424, doi:10.1029/95GL01093.
Ward, R., A. T. Williams, J. A. Barker, L. J. Brewerton, and I. N. Gale (1998), Groundwater tracer tests: A review and guidelines for their use in British aquifers, R\&D Tech. Rep. W160, Environ. Agency, London.

West, L. J., and N. E. Odling (2007), Characterization of a multilayer aquifer using open well dilution tests, Ground Water, 45(1), 74-84, doi:10.1111/j.1745-6584.2006.00262.x.

Wheater, H. S., D. Peach, and A. Binley (2007), Characterising groundwaterdominated lowland catchments: The UK Lowland Catchment Research Programme (LOCAR), Hydrol. Earth Syst. Sci., 11(1), 108-124.

Williams, A., J. Bloomfield, K. Griffiths, and A. Butler (2006), Characterising the vertical variations in aquifer properties within the Chalk aquifer, J. Hydrol., 330, 53-62, doi:10.1016/j.jhydrol.2006.04.036.

Witthuser, K., H. Hotzl, B. Reichert, W. Stichler, and R. Nativ (2000), Laboratory experiments for diffusion transport processes in fractured chalk, in Tracers and Modelling in Hydrogeology, edited by A. Dassargues, IAHS Publ., 262, 303-308.

Witthuser, K., B. Reichert, and H. Hotzl (2003), Contaminant transport in fractured chalk: Laboratory and field experiments, Ground Water, 41(6), 806-815, doi:10.1111/j.1745-6584.2003.tb02421.x.

Witthuser, K., D. Arnepalli, and D. N. Singh (2006), Investigations on diffusion characteristics of granite and chalk rock mass, Geotech. Geol. Eng., 24, 325-334, doi:10.1007/s10706-004-7549-y.

Zhou, Q., H. H. Liu, G. S. Bodvarsson, and F. J. Molz (2006), Evidence of multi-process matrix diffusion in a single fracture from a field tracer test, Transp. Porous Media, 63, 473-487, doi:10.1007/s11242-005-1123-9.

Zhou, Q., H. H. Liu, F. J. Molz, Y. Zhang, and G. S. Bodvarsson (2007), Fieldscale effective matrix diffusion coefficient for fractured rock: Results from literature survey, J. Contam. Hydrol., doi:10.1016/j.jconhyd.2007.02.002, in press.

A. P. Butler and S. A. Mathias, Department of Civil and Environmental Engineering, Imperial College London, London SW7 2AZ, UK. (simon. mathias@imperial.ac.uk)

D. W. Peach and A. T. Williams, British Geological Survey, Wallingford OX10 8BB, UK. 